\title{
MEMBANGUN POLA BERPIKIR ILMIAH ANAK USIA DINI MELALUI PEMBELAJARAN IPA DAN MATEMATIKA POS PAUD MELATI KEL PASIRKALIKI KEC CIMAHI UTARA
}

\author{
Ratu Fenny Muldiani' ${ }^{1}$, Siti Samsiyah Purwaningsih ${ }^{2}$, \\ Kunlestiowati Hadiningrum ${ }^{3}$, Nani Yuningsih ${ }^{4}$ \\ 1,2,3,4 Unit Pelayanan Mata Kuliah Umum, Politeknik Negeri Bandung 40012 \\ e-mail: ${ }^{1}$ ratu.fenny@ polban.ac.id, ${ }^{2}$ sitisamsiyahpurwaningsih@yahoo.co.id \\ knlestiowati@polban.ac.id, ${ }^{4}$ naniyuningsih@polban.ac.id
}

\begin{abstract}
Abstrak
Alat peraga edukasi (APE) IPA dan Matematika selain dapat digunakan sebagai alat permainan dapat juga dimanfaatkan untuk membangun pola berfikir ilmiah anak. APE dapat dimanfaatkan untuk menggali kemampuan, melatih konsentrasi, dan memperkenalkan konsep logika sederhana. Kegiatan Pengabdian Pada Masyarakat tahun 2017 ini menghasilkan solusi untuk POS PAUD Melati Kelurahan Pasirkalili berupa bantuan APE IPA dan Matematika yang sesuai dengan kebutuhan kurikulum pendidikan anak usia dini dalam mendukung proses belajar mengajar. Bantuan disertai modul penggunaan APE sebagai pegangan untuk para pendidik (guru). Keseluruhan kegiatan telah terlaksana dengan tuntas, terjadi komunikasi yang efisien dan efektif dengan mitra sehingga tim pengabdian mendapatkan kelancaran dalam menjalankan tugasnya sesuai dengan rencana. Hasil evaluasi menunjukkan mayoritas jawaban responden pada seluruh item pertanyaan kuisioner adalah "sangat setuju" dan "setuju". Dengan demikian dapat disimpulkan bahwa responden merasakan manfaat dengan terbentuknya pola berpikir ilmiah siswanya melalui bantuan APE dari tim pengabdian masyarakat Polban. Hasil wawancara semua guru menyatakan bahwa bantuan APE yang diberikan dari tim pengabdian Polban sangat mendukung kegiatan proses belajar mengajar. Pasca pelatihan tim pengabdian masyarakat tetap melakukan monitoring dan pendampingan kepada mitra untuk memastikan keberlangsungan program setelah pelatihan.
\end{abstract}

Kata Kunci : POS PAUD, Alat Peraga Edukatif, IPA dan Matematika

\section{PENDAHULUAN}

PAUD adalah jenjang pendidikan sebelum jenjang pendidikan dasar yang merupakan suatu upaya pembinaan yang ditujukan bagi anak sejak lahir sampai dengan usia enam tahun yang dilakukan melalui pemberian rangsangan pendidikan untuk membantu pertumbuhan dan perkembangan jasmani dan rohani agar anak memiliki kesiapan dalam memasuki pendidikan lebih lanjut, yang diselenggarakan pada jalur formal dan nonformal.
Menurut Akbar dalam Psikologi Perkembangan Anak, mengenal sifat, bakat dan kemampuan, PAUD merupakan salah satu bentuk penyelenggaraan pendidikan yang menitik beratkan pada peletakan dasar ke arah pertumbuhan dan lima perkembangan, yaitu: perkembangan moral dan agama, perkembangan fisik (koordinasi motorik halus dan kasar), kecerdasan/kognitif (daya pikir, daya cipta), sosio emosional (sikap dan emosi) bahasa dan komunikasi, sesuai dengan keunikan dan tahap-tahap perkembangan 
kelompok usia yang dilalui oleh anak usia dini.

Selain pengajar terdapat faktor yang sangat berpengaruh terhadap keberhasilan suatu program pendidikan diantaranya adalah tersedianya berbagai fasilitas pendidikan berupa sarana dan prasarana yang memadai seperti lingkungan yang sehat, kapasitas ruang belajar yang cukup salah satunya sesuai jumlah peserta didik, tersedianya alat peraga pendidikan (APE) dan yang tidak kalah pentingnya adalah kompetensi guru yang sesuai dengan tujuan kurikulum PAUD.

Dalam proses belajar mengajar untuk menghasilkan pola berpikir ilmiah sejak dini, dapat dibantu dengan alat peraga edukatif (APE) IPA dan Matematika yang merupakan sarana /media untuk menghantarkan anak lebih memahami materi yang disampaikan serta memotivasi dan merangsang anak bereksplorasi.

Strategi pembelajaran yang dapat mengoptimalkan pendidikan pada anak usia dini, yakni melalui pembelajaran berbasis otak (brainbased learning) agar dapat mengembangkan pola berpikir antara lain dengan prinsip menciptakan lingkungan belajar yang dapat membuat anak asyik dalam pengalaman belajar, yaitu melalui APE. (Qudsyil, 2010)

APE IPA dan Matematika yang dapat digunakan sebagai alat permainan untuk mengoptimalkan perkembangan anak sesuai dengan usia serta tingkat perkembangan anak. Melalui Alat peraga, bisa memperkenalkan konsep logika sederhana, yaitu anak dilatih berpikir logis dengan mengikuti urutan atau aturan sederhana sesuai dengan penggunaannya. Misalnya dalam permainan menyusun balok anak diarahkan untuk berpikir balok yang besar lebih baik diletakan di bagian bawah sebagai pondasi agar tidak menggangu keseimbangan bangunan yang dibuatnya.

Menurut Morisson, salah satu pembelajaran yang dapat menstimulasi perkembangan kognitif anak yaitu kegiatan pengenalan sains sederhana. Dalam perkembangannya, sains semakin memerankan peran penting pada kurikulum Taman Kanak-kanak.

Dari hasil survei pendahuluan pada POS PAUD Melati diperoleh informasi bahwa para pengajar POS PAUD Melati adalah warga setempat yang bekerja secara sukarela, dengan kondisi, sarana prasarana dan lingkungan yang minim dalam upaya mencapai tujuan kurikulum PAUD. Untuk mencapai tujuan kurikulum khususnya dalam membangun pola berfikir ilmiah anak usia dini melalui pembelajaran IPA dan Matematika, POS PAUD Melati perlu diberi bantuan berupa alat peraga yang berkaitan dengan pembelajaran IPA dan Matematika beserta arahan dan bimbingan untuk para pengajar tentang penggunaannya.

POS PAUD Melati berdiri di atas bangunan semi permanen di atas tanah sewa dari warga di jl Gunung Rahayu II Rancabali RT 03 RW 10 Kelurahan Pasirkaliki Kecamatan Cimahi Utara Kota Cimahi. (Gambar 1) 

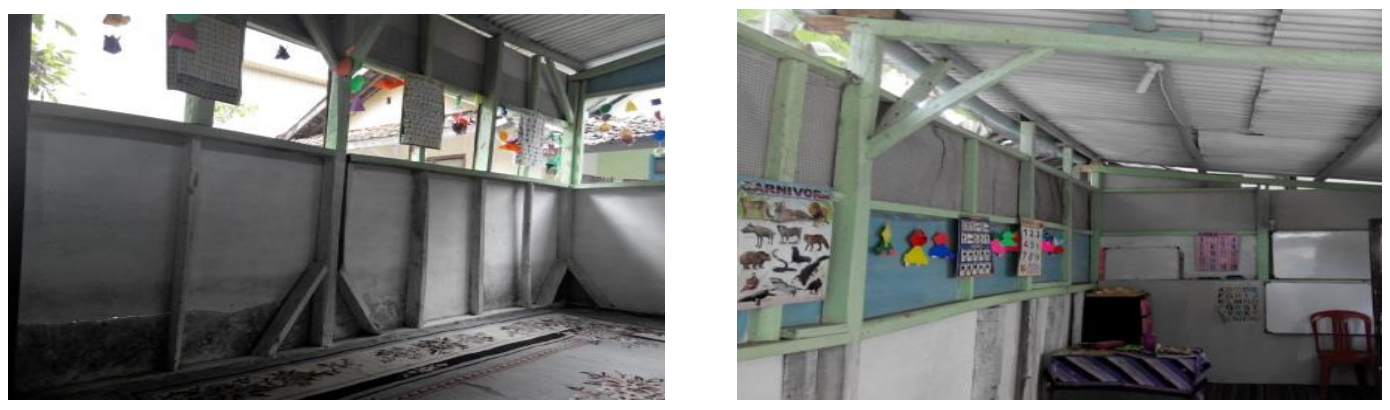

Gambar 1. Ruang Kelas POS PAUD Melati saat ini

Untuk memberikan gambaran kondisi dan lingkungan POS PAUD Melati seperti ditunjukkan pada gambar
2, terlihat keterbatasan sarana prasarana pendidikan pada POS PAUD Melati.

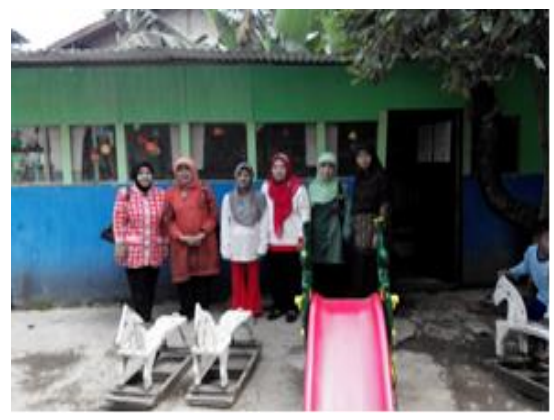

Gambar 2. Kondisi POS PAUD Melati

Sasaran program POS PAUD Melati adalah anak yang berasal dari keluarga pra sejahtera pada rentang usia 3-6 tahun, saat ini tercatat sebanyak 54 peserta didik (terbagi dalam dua waktu belajar). Keterbatasan sumber dana operasional POS PAUD Melati dapat
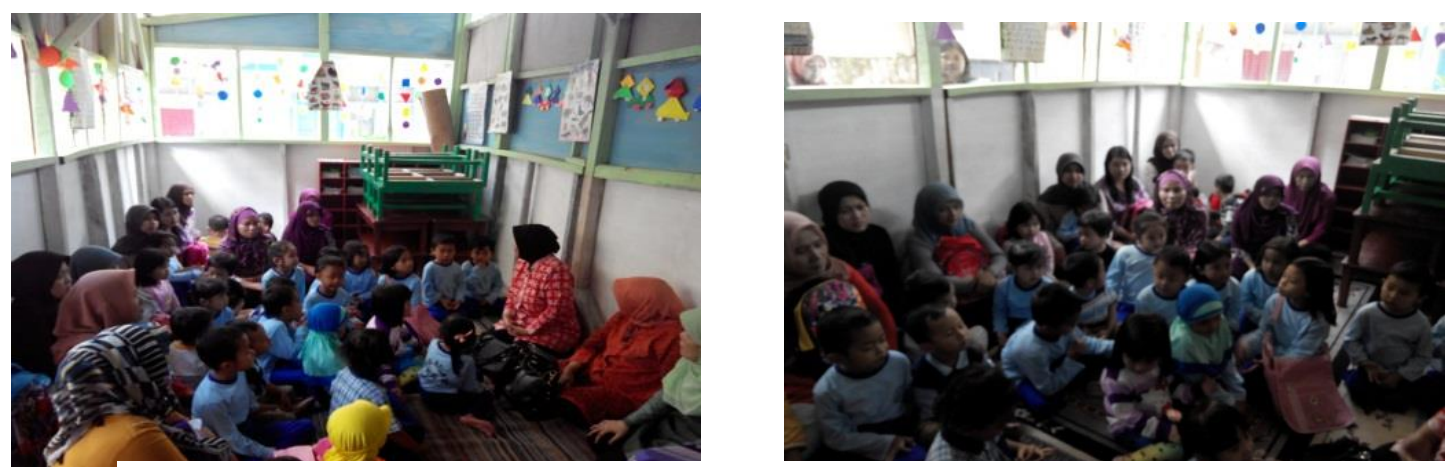

Gambar 3. Susana Kegiatan Belajar di POS PAUD Melati terlihat dari minimnya sarana prasarana pembelajaran yang tersedia, khusunya APE IPA dan Matematika. Gambar 3 memperjelas informasi tentang suasana saat belajar dan keterbatasan kondisi ruang belajar. 
Merujuk pada uraian di atas kegiatan Pengabdian Pada Masyarakat ini menawarkan solusi untuk POS PAUD Melati berupa bantuan APE IPA dan Matematika yang sesuai dengan kebutuhan kurikulum pendidikan anak usia dini dalam mendukung proses belajar mengajar disertai modul penggunaan alat peraga edukatif tersebut untuk para pendidik (guru).

Target dalam kegiatan program Pengabdian Pada Masyarakat ini adalah sebagai berikut:

1) Tersedianya APE IPA dan Matematika sesuai kebutuhan untuk jenjang anak usia dini.

2) Bertambahnya keterampilan para guru dalam kegiatan belajar mengajar dengan menggunakan bantuan APE IPA dan Matematika tersebut melalui bimbingan dalam kegiatan pengabdian ini beserta modul penggunaannya.

3) Meningkatkan antusiasme belajar dan kemampuan berfikir ilmiah anak-anak usia dini di POS PAUD Melati.

Luaran kegiatan Pengabdian Masyarakat ini adalah :

1. Tersedianya APE IPA dan Matematika di POS PAUD Melati.

2. Modul penggunaan APE IPA dan Matematika untuk Anak Usia Dini di POS PAUD Melati.

3. Publikasi hasil kegiatan pengabdian.

\section{METODE}

Metode pelaksanaan kegiatan pengabdian bagi masyarakat ini adalah berupa studi literatur, wawancara, survey lapangan, diskusi, demonstrasi, dan bimbingan kepada para guru/pendidik. Secara teknis pelaksanaan program dapat diuraikan dengan tahapan-tahapan sebagai berikut.

1. Studi literatur dan wawancara dengan Pengurus HIMPAUDI Cabang Cimahi (Himpunan Pendidik dan Tenaga Kependidikan Anak Usia Dini, lembaga masyarakat independen yang bergerak dalam bidang pendidikan khususnya anak usia dini) tentang jumlah anak usia dini, pengelompokan keluarga berdasarkan kemampuan ekonomi dalam menyekolahkan putraputrinya.

2. Survey lapangan ke POS PAUD yang membutuhkan alat peraga IPA dan Matematika, dalam rangka penentuan mitra.

3. Menyiapkan modul dan alat peraga IPA dan Matematika yang akan digunakan untuk pelatihan guru PAUD mitra.

4. Memberikan bimbingan penggunaan alat peraga IPA dan Matematika bagi guru/pendidik pada mitra yang terpilih dalam kegiatan pengabdian ini.

5. Melakukan evaluasi dengan cara memberikan kuisioner kepada orang tua siswa untuk mengetahui manfaat kegiatan terhadap perubahan semangat belajar siswa.

6. Penyusunan laporan akhir dan publikasi hasil kegiatan pengabdian ini.

Untuk lebih memperjelas tahap-tahap kegiatan pengabdian ini, dibuat kerangka tahapan seperti pada gambar 4 


\begin{tabular}{|c|l|}
\hline $\begin{array}{c}\text { STUDI } \\
\text { PENDAHULUAN }\end{array}$ & $\begin{array}{l}\text { Mitra : Keterbatasan alat Peraga IPA dan } \\
\text { Matematika sebagai pendukung proses belajar }\end{array}$ \\
\hline PENYELESAIAN \\
MASALAH
\end{tabular}

Gambar 4. Tahapan Kegiatan Pengabdian Masyarakat

\section{HASIL DAN PEMBAHASAN}

1. Studi pendahuluan pada POS PAUD

Melati sebagai pendahuluan untuk
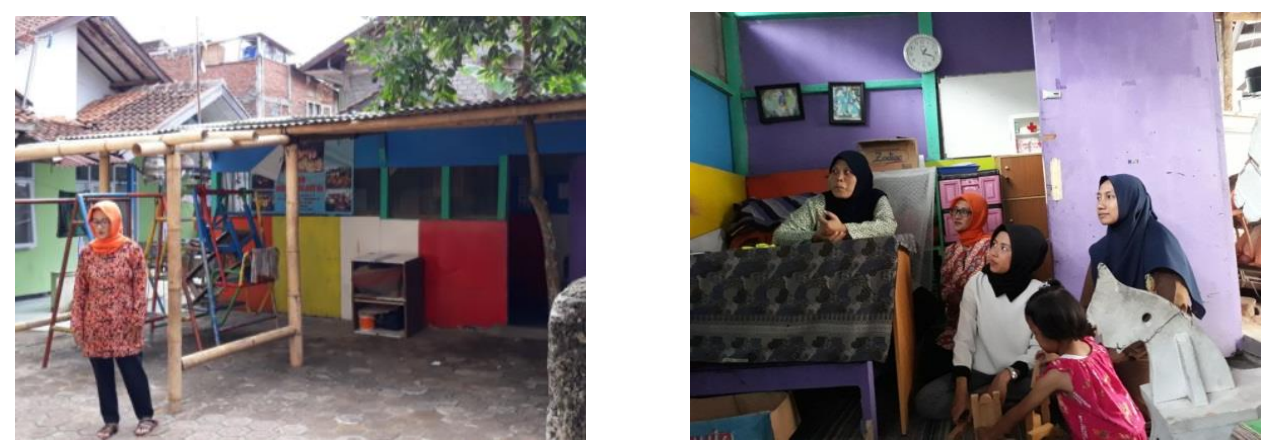

Gambar 5. Studi Pendahuluan ke POS PAUD Melati

Hasil yang dicapai dari kegiatan ini adalah informasi tentang POS PAUD Melati disertai
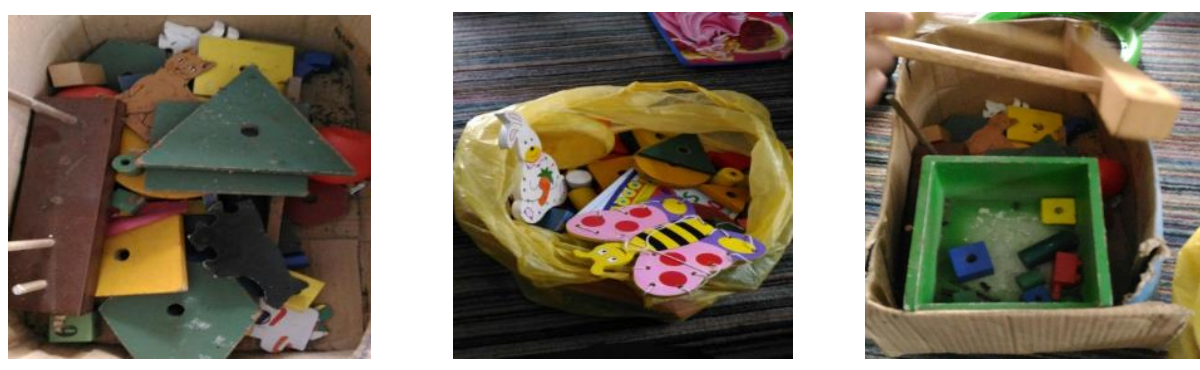

Gambar 6. Alat Peraga Edukatif yang dimiliki oleh POS PAUD Melati 
3. Kunjungan ke Kolompok Bermain Flamboyan di Kota Bandung yang telah menggunakan APE IPA dan
Matematika dalam kegiatan belajar mengajar
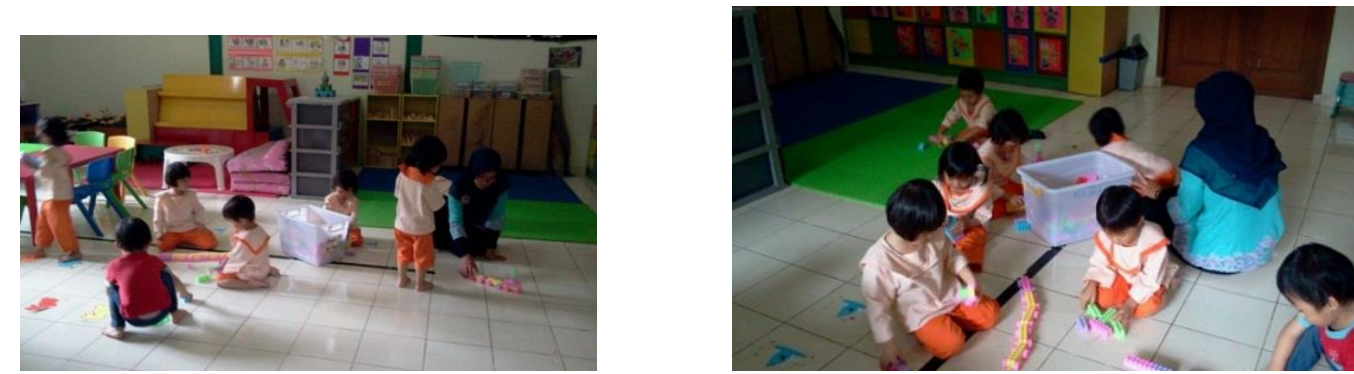

Gambar 7. Kegiatan Kunjungan ke Kolompok Bermain Flamboyan

Hasil yang dicapai dari kegiatan kunjungan ke Kolompok Bermain Flamboyan adalah informasi dan masukan, sekaligus sebagai perbandingan bagi tim pengabdian tentang kelengkapan yang dibutuhkan dan manfaat dari penggunaan APE IPA dan Matematika dalam kegiatan belajar mengajar. Sebagai parameter bagi tim pengabdian dalam penyediaan modul dan alat peraga edukatif.

Fokus materi IPA dan Matematika yang akan dikembangkan dalam pembuatan modul adalah pengenalan bentuk geometri, angka huruf dan berhitung, hewan, tumbuhan, anggota tubuh, serta pengenalan lingkungan. Pola berfikir ilmiah harus didukung dengan alat/sarana yang baik. Sarana ilmiah pada dasarnya merupakan alat bantu kegiatan ilmiah dalam berbagai langkah yang harus ditempuh. Selanjutnya menentukan APE IPA dan Matematika yang diperlukan untuk mendukung pembelajaran dalam membangun pola berfikir ilmiah anak usia dini.

4. Pelatihan penggunaan alat peraga edukatif

Dalam upaya untuk mencapai target kegiatan pengabdian, yaitu meningkatkan wawasan dan keterampilan guru di POS PAUD Melati dalam menggunaan APE , dilanjutkan dengan pelatihan penggunaan APE dalam kegiatan belajar mengajar. Gambar 8 menunjukkan kegiatan pelatihan.
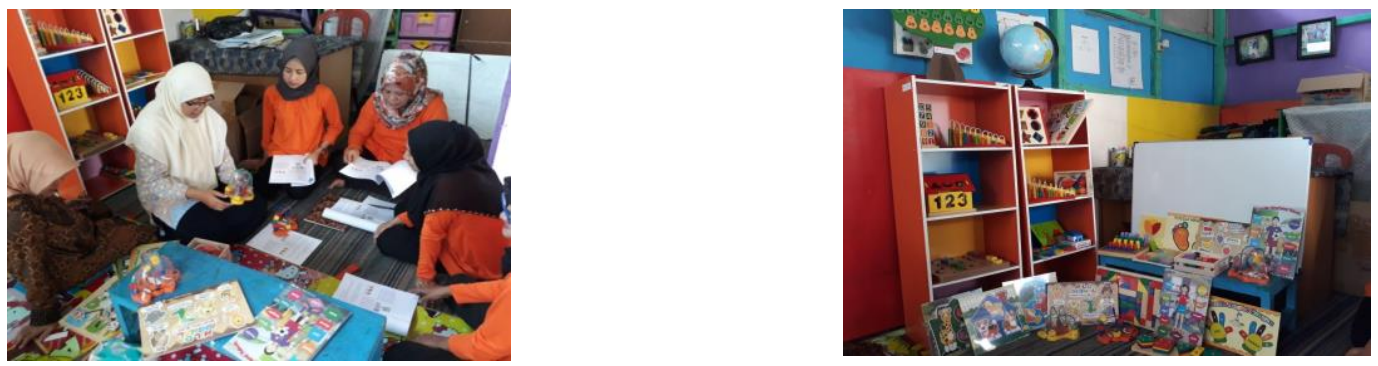

Gambar 8. Kegiatan Pelatihan di POS PAUD Melati 
5. Analisis Deskriptif Evaluasi

Kegiatan Pengabdian

Untuk mengetahui apakah bantuan APE dapat berpengaruh positif terhadap suasana belajar dalam mengembangkan pola berpikir ilmiah di POS PAUD Melati, dibuat kuesioner dengan responden orang tua siswa POS PAUD Melati. Pengambilan responden dari orang tua siswa dikarenakan orang tua siswa bisa melihat langsung perkembangan putra-putrinya dari hasil proses belajar mengajar setelah mendapatkan bantuan APE. Responden diambil dari 53 orang tua siswa dengan 10 item pertanyaan seperti terlihat pada tabel 1. Item pertanyaan diarahkan pada manfaat penggunaan APE dalam mendukung pola berpikir ilmiah bagi siswa POS PAUD Melati, sesuai dengan tujuan bantuan APE agar siswa terbiasa dengan pola berpikir ilmiah melalui permainan yang sesuai kurikulum PAUD. Permainan edukatif adalah permainan yang memberikan pengalaman belajar untuk memberikan nilai edukatif bagi anak, mampu mengembangkan aspek pada perkembangan anak dan berpengaruh terhadap kemampuan pemecahan masalah.

Tabel 1 merupakan hasil jawaban responden atas item pertanyaan kuesioner yang diberikan.

Tabel 1. Banyaknya Responden Berdasarkan Jawaban Item Pertanyaan

\begin{tabular}{|c|c|c|c|c|c|c|c|c|c|c|c|}
\hline \multirow{3}{*}{ No } & \multirow{3}{*}{ Pertanyaan } & \multicolumn{10}{|c|}{ Jawaban } \\
\hline & & \multicolumn{2}{|c|}{$\begin{array}{c}\text { Tidak } \\
\text { Setuju }\end{array}$} & \multicolumn{2}{|c|}{$\begin{array}{c}\text { Kurang } \\
\text { Setuju }\end{array}$} & \multicolumn{2}{|c|}{ Cukup Setuju } & \multicolumn{2}{|c|}{ Setuju } & \multicolumn{2}{|c|}{ Sangat Setuju } \\
\hline & & Frek. & $\%$ & Frek. & $\%$ & Frek. & $\%$ & Frek. & $\%$ & Frek. & $\%$ \\
\hline 1 & $\begin{array}{l}\text { APE IPA dan Matematika } \\
\text { memperjelas pelajaran yang } \\
\text { disampaikan guru }\end{array}$ & & & & & & & 33 & 62,21 & 20 & 37,73 \\
\hline 2 & $\begin{array}{l}\text { APE IPA dan Matematika } \\
\text { meningkatkan semangat belajar } \\
\text { anak }\end{array}$ & & & & & & & 22 & 41,17 & 31 & 52,83 \\
\hline 3 & $\begin{array}{l}\text { APE IPA dan Matematika } \\
\text { menciptakan situasi belajar } \\
\text { melalui bermain yang } \\
\text { menyenangkan bagi anak }\end{array}$ & & & & & & & 13 & 24,53 & 40 & 75,47 \\
\hline 4 & $\begin{array}{l}\text { Melalui APE IPA dan Matematika } \\
\text { anak akan mencoba melakukan } \\
\text { berbagai kegiatan yang } \\
\text { merekasukai, seperti menyusun } \\
\text { balok (sesuai dengan bentuk atau } \\
\text { warna) }\end{array}$ & & & & & 8 & 15,09 & 25 & 47,17 & 20 & 37,74 \\
\hline 5 & $\begin{array}{l}\text { APE memfasilitasi anak-anak } \\
\text { membua thubungan yang } \\
\text { harmonis dan komunikatif } \\
\text { denganteman- temannya, karena } \\
\text { dalam kegiatan pembelajaran } \\
\text { siswa dikelompokkan. }\end{array}$ & & & & & 14 & 26,41 & 16 & 30,19 & 23 & 43,40 \\
\hline 6 & $\begin{array}{l}\text { APE dapat memperkenalkan } \\
\text { bangun dan warna dengan baik } \\
\text { terhadap anak }\end{array}$ & & & & & & & 23 & 43,39 & 30 & 56,61 \\
\hline
\end{tabular}




\begin{tabular}{||l|l|l|l|l|l|l|l|l|l||}
\hline 7 & $\begin{array}{l}\text { Saat memainkan APE, seperti } \\
\text { puzzle akan melatih konsentrasi } \\
\text { anak }\end{array}$ & & & & & & & & \\
\hline 8 & $\begin{array}{l}\text { Dengan adanya APE di sekolah } \\
\text { anak lebih semangat pergi ke } \\
\text { sekolah }\end{array}$ & & & & & & & & \\
\hline & $\begin{array}{l}\text { Dengan adanya APE di sekolah } \\
\text { orang tua lebih percaya diri } \\
\text { anaknya disekolahkan di tempat } \\
\text { tersebut }\end{array}$ \\
$\begin{array}{l}\text { Dengan adanya APE, anak } \\
\text { banyak menyampaikan } \\
\text { pertanyaan yang berhubungan } \\
\text { dengan permainan / alat yang } \\
\text { sudah dicoba di sekolah ketika } \\
\text { sampai di rumah }\end{array}$
\end{tabular}

Pada item pertanyaan 1 sd 10 tidak ada yang menjawab pilihan jawaban"tidak setuju" maupun "kurang setuju". Pada item pertanyaan $4,5,7$, dan 10 terdapat jawaban responden pada pilihan "cukup setuju". Mayoritas jawaban responden pada seluruh item pertanyaan adalah pada jawaban "sangat setuju" dan "setuju”.Dengan demikian dapat disimpulkan bahwa responden merasakan pengaruh lebih baik atas bantuan APE yang diberikan tim pengabdian masyarakat dari Polban terhadap proses belajar mengajar di POS PAUD Melati.

\section{KESIMPULAN}

Telah terjadi komunikasi yang efisien dan efektif dengan mitra sehingga tim pengabdian masyarakat mendapatkan kelancaran dalam menjalankan tugasnya sesuai dengan rencana. Dapat diambil beberapa kesimpulan sebagai berikut:

1. Kegiatan studi pendahuluan pada mitra POS PAUD Melati menunjukkan kondisi dan permasalahan yang masih sama dibandingkan ketika survey pendahuluan penentuan mitra saat menyusun proposal.
2. Kegiatan kunjungan ke Kelompok Bermain Flamboyan memberikan perbandingan perlunya peningkatan terutama dalam pengadaan dan penyediaan alat peraga edukatif di POS PAUD Melati.

3. Berdasarkan kuesioner yang diberikan kepada orang tua siswa Pos Paud Melati (sebagai responden), dengan pertanyaan mengarah pada manfaat penggunaan APE dalam mendukung pola berpikir ilmiah bagi siswa Paud. Responden tidak ada yang menjawab pilihan jawaban "tidak setuju" maupun "kurang setuju". Dengan demikian dapat disimpulkan bahwa responden merasakan manfaat atas bantuan APE yang diberikan tim pengabdian masyarakat dari Polban terhadap proses belajar mengajar di Pos Paud Melati untuk pengembangan pola berpikir ilmiah bagi putraputrinya.

4. Sedangkan bardasarkan hasil wawancara dengan semua guru Pos Paud Melati, didapatkan 
informasi bahwa APE yang terdapat di Pos Paud Melati masih jauh dari yang seharusnya, khususnya APE bidang IPA dan Matematika. Sehingga semua guru menyatakan bahwa bantuan APE yang diberikan dari tim pengabdian masyarakat Polban sangat mendukung kegiatan proses belajar mengajar khususnya dalam membentuk pola berpikir ilmiah untuk para siswanya.

5. Tetap melakukan monitoring dan pendampingan pasca kegiatan kepada mitra untuk mengetahui penggunaan alat peraga edukatif dalam kegiatan belajar mengajar.

\section{DAFTAR PUSTAKA}

Akbar, Reni-Hawadi. 2008. Psikologi Perkembangan Anak, Mengenal Sifat, Bakat dan Kemampuan Anak. Jakarta: Grasindo.

Handoko Martin. 2004. Pendidikan Usia Dini. Jakarta: Grasindo.

Martuti,A. 2008. Mengelola PAUD dengan Aneka Permainan Meraih Kecerdasan Majemuk. Yogyakarta: Kreasi Wacana.

Morrison, George S. 2012. Dasar-Dasar Pendidikan Anak Usia Dini (PAUD) Jakarta: Indeks.

Qudsyi1, Hazhira. 2010. Optimalisasi Pendidikan Anak Usia DiniMelalui Pembelajaran Yang Berbasis Perkembangan Otak. Buletin Psikologi Fakultas Psikologi Universitas Gadjah Mada Volume 18, No. 2, 2010: 91 - 111 ISSN: 0854-7108. 